\title{
Cardiac and renal function are progressively impaired with aging in Zucker diabetic fatty type II diabetic rats
}

\author{
John Baynes' and David B. Murray ${ }^{2, *}$ \\ ${ }^{1}$ Department of Exercise Science; University of South Carolina; Columbia, SC USA; and ${ }^{2}$ Department of Pharmacology; University of Mississippi School of \\ Pharmacy; Oxford, MS USA
}

Key words: cardiomyopathy, diabetes, hydronephrosis

\begin{abstract}
This study investigated the temporal relationship between cardiomyopathy and renal pathology in the type II diabetic Zucker diabetic fatty (ZDF) rat. We hypothesized that changes in renal function will precede the development of cardiac dysfunction in the ZDF rat. Animals (10 weeks old) were divided into four experimental groups: Lean Control (fa/?) LC $(n=7)$, untreated ZDF rats $(n=7)$ sacrificed at 16 weeks of age, and LC $(n=7)$ untreated ZDF rats $(n=9)$ sacrificed at 36 weeks of age. LV structural/functional parameters were assessed via Millar conductance catheter. Renal function was evaluated via markers of proteinuria and evidence of hydronephrosis. LV mass was significantly less in the ZDF groups at both time points compared to age-matched LC. End diastolic volume was increased by $16 \%$ at 16 weeks and by $37 \%$ at 36 weeks of age ( $p<0.05$ vs. LC). End diastolic pressure and end systolic volume were significantly increased $(42 \%$ and $27 \%$ respectively) at 36 weeks of age in the ZDF compared to LC. Kidney weights were significantly increased at both 16 and 36 week in ZDF animals $(p<0.05$ vs. LC). Increased urinary albumin and decreased urinary creatinine were paralleled by a marked progression in the severity of hydronephrosis from 16 to 36 weeks of age in the ZDF group. In summary, there is evidence of progressive structural and functional changes in both the heart and kidney, starting as early as 16 weeks, without evidence that one pathology precedes or causes the other in the ZDF model of type II diabetes.
\end{abstract}

\section{Introduction}

Several European epidemiologic studies reveal the catastrophic and interrelated complications of cardiorenal failure in the diabetic population (DREAM, ${ }^{1}$ LIRICO, ${ }^{2} \mathrm{HOPE}^{3}$ and FRAMINGHAM ${ }^{4}$ ). However, in the United States the clinical manifestation and significance of the combined effects of cardiovascular and renal disease remain underappreciated. Currently, the number of diabetics in the United States is estimated at 23.4 million people or $7.8 \%$ of entire population. ${ }^{5,6}$ Despite the numerous pathologies associated with type II diabetes, nearly $2 / 3^{\text {rds }}$ of all diabetic patients die of heart failure. ${ }^{7}$ However, the contribution of renal dysfunction to the onset of myocardial dysfunction in diabetes, independent of ischemic disease, remains unknown.

Numerous studies investigating the effects of Type II diabetes on the heart have used the Zucker diabetic fatty (ZDF) rat model. ${ }^{8}$ Likewise, investigators examining diabetes-induced nephropathy have also employed the ZDF rat. ${ }^{9}$ Although there is an association between decreased renal function and increased cardiovascular morbidity/mortality, ${ }^{10,11}$ few studies have examined the correlative onset of each of these disease states and the impact they have on the overall progression of pathologic changes in individual organ systems. ${ }^{12,13}$ Moreover, the time points selected in various separate studies on the heart and kidney in diabetic rats differ significantly, which further confounds the ability to determine the relationship between these pathologies. To address the temporal relationship between renal and cardiovascular pathology in diabetes, this study examines left ventricular (LV) remodeling and systolic/diastolic functional parameters and renal morphology and function in the same animals at two time points, 16 and 36 weeks of age. These time points were chosen as they best correspond to the early (14-17 weeks of age) and later stage (24-37 weeks of age) ranges of animal ages used in previous studies, focused on either cardiac or renal pathophysiology. ${ }^{13-18}$ We hypothesize the ZDF animal model of type II diabetes will display systolic and diastolic dysfunction at the earlier time point prior to development of renal pathology. Whereas we believe there will be significant loss of systolic and diastolic ventricular function at 36 weeks of age, which corresponds to the severity of renal pathology.

\section{Results}

Comparison of body and LV weights between lean control and ZDF rats. By 16 weeks of age ZDF animals weighed significantly more than their age-matched LC group. However, at 36 
Table I. Comparison of whole body, LV and kidney weights in LC and ZDF rats at 16 and 36 weeks of age

\begin{tabular}{|c|c|c|c|c|c|}
\hline & $\begin{array}{l}\text { Body weight } \\
\text { (gm) }\end{array}$ & $\begin{array}{l}\text { LV weight } \\
\text { (mg) }\end{array}$ & $\begin{array}{l}\text { Left kidney weight } \\
\text { (mg) }\end{array}$ & $\begin{array}{c}\text { Right kidney weight } \\
\text { (mg) }\end{array}$ & $\begin{array}{l}\text { Blood glucose } \\
(\mathbf{m g} / \mathrm{dl})\end{array}$ \\
\hline \multicolumn{6}{|c|}{16 weeks of age } \\
\hline Lean Control & $329 \pm 25$ & $917 \pm 47$ & $1300 \pm 95$ & $1296 \pm 64$ & $105 \pm 15$ \\
\hline ZDF & $413 \pm 3 I^{*}$ & $850 \pm 50 *$ & $1939 \pm 109 *$ & $1960 \pm 250 *$ & $545 \pm 52 *$ \\
\hline \multicolumn{6}{|c|}{36 weeks of age } \\
\hline Lean Control & $456 \pm 11$ & $920 \pm 32$ & $|27| \pm 94$ & $1282 \pm 85$ & $105 \pm 7$ \\
\hline
\end{tabular}

All values are reported as mean $\pm S D$. *denotes $p \leq 0.05$ compared to age-matched LC rats.

Table 2. Comparison of in vivo left ventricular functional parameters in lean control (LC) and zucker diabetic fatty (ZDF) rats at I6 and 36 weeks of age

\begin{tabular}{|c|c|c|c|c|c|c|c|c|c|}
\hline & $\begin{array}{l}\text { Heart } \\
\text { rate } \\
(\text { bpm) }\end{array}$ & $\begin{array}{c}\text { End } \\
\text { systolic } \\
\text { pressure } \\
(\mathbf{m m H g})\end{array}$ & $\begin{array}{c}\text { End } \\
\text { diastolic } \\
\text { pressure } \\
(\mathbf{m m H g})\end{array}$ & $\begin{array}{c}\text { End } \\
\text { systolic } \\
\text { volume } \\
(\mu \mathrm{I})\end{array}$ & $\begin{array}{l}\text { End } \\
\text { diastolic } \\
\text { volume } \\
(\mu \mathrm{I})\end{array}$ & $\begin{array}{c}\text { Cardiac } \\
\text { output } \\
(\mathrm{ml} / \mathrm{min})\end{array}$ & $\begin{array}{c}\text { Stroke } \\
\text { volume } \\
(\mu \mathrm{l})\end{array}$ & $\begin{array}{c}\text { Volume } \\
@ \text { Min \& } \\
\text { Max } \\
\text { dP/dt }(\mu l)\end{array}$ & $\begin{array}{c}\text { Min \& Max } \\
\text { dV/dt } \\
(\mu l / s e c)\end{array}$ \\
\hline \multicolumn{10}{|l|}{$\begin{array}{c}16 \text { weeks of } \\
\text { age }\end{array}$} \\
\hline Lean Control & $282 \pm 10$ & $|2| \pm 3$ & $9 \pm 1$ & $196 \pm 22$ & $306 \pm 23$ & $31 \pm 5$ & $110 \pm 16$ & $\begin{array}{l}206 \pm 25 \\
301 \pm 24\end{array}$ & $\begin{array}{r}-2134 \pm 400 \\
2778 \pm 330\end{array}$ \\
\hline ZDF & $282 \pm 35$ & $117 \pm 16$ & $10 \pm 1$ & $200 \pm 13$ & $355 \pm 4^{*}$ & $44 \pm 7$ & $155 \pm 16 *$ & $\begin{array}{c}227 \pm 17 \\
364 \pm 19 *\end{array}$ & $\begin{array}{c}-2268 \pm 372 \\
3251 \pm 284\end{array}$ \\
\hline \multicolumn{10}{|l|}{$\begin{array}{c}36 \text { weeks of } \\
\text { age }\end{array}$} \\
\hline Lean Control & $265 \pm 10$ & $124 \pm 5$ & $7 \pm 1$ & $299 \pm 16$ & $367 \pm 12$ & $36 \pm 3$ & $138 \pm 13$ & $\begin{array}{l}238 \pm 19 \\
350 \pm 12\end{array}$ & $\begin{array}{r}-3267 \pm 200 \\
3750 \pm 540\end{array}$ \\
\hline ZDF & $235 \pm 10$ & $125 \pm 8$ & $10 \pm I^{*}$ & $380 \pm 34 *$ & $504 \pm 34 *$ & $29 \pm 2$ & $123 \pm 5$ & $\begin{array}{l}394 \pm 35^{*} \\
497 \pm 35^{*}\end{array}$ & $\begin{array}{c}-2643 \pm 325^{*} \\
2819 \pm 260^{*}\end{array}$ \\
\hline
\end{tabular}

Values are presented as mean \pm SEM. *denotes $p<0.05$ versus age-matched LC rats. $n \geq 6$ per group. dP/dt $=$ an indicator of myocardial contractility (maximum or minimum first derivative of $\mathrm{LV}$ pressure) $\mathrm{dV} / \mathrm{dt}_{\max }=$ left ventricular ejection rate during systole, and $\mathrm{dV} / \mathrm{dt}_{\min }=$ peak rate of passive diastolic filling of the left ventricle.

weeks there was a marked reduction of body weight in the ZDF group (Table 1). Blood glucose was significantly elevated in the ZDF group compared to LC at both 16 and 36 weeks of age. LV mass was significantly decreased in the ZDF groups at both time points compared to age matched LC. These trends were also evident when normalized to tibial lengths.

Left ventricular morphology and functional assessment. Table 2 details ventricular structural and functional parameters for all groups. Mean arterial blood pressure was not significantly different between ZDF and LC at 16 weeks of age $(113 \pm 11$ vs. $102 \pm 4 \mathrm{mmHg}$; ZDF vs. LC) or at 36 weeks of age $(108 \pm 6 \mathrm{~mm}$ vs. $113 \pm 5 \mathrm{Hg}$; ZDF vs. LC respectively). End diastolic volume (EDV) in ZDF rats was increased by $16 \%$ at 16 weeks and increased by $37 \%$ at 36 weeks of age relative to age-matched LC. The change in chamber volume was mirrored by a significant increase in end diastolic pressure (EDP) (42\% increase) at 36 weeks of age which was not seen at 16 weeks. Additionally, at 36 weeks end systolic volume (ESV) was markedly increased (27\%) compared to age matched LC, but, again, this change in ESV was not evident at 16 weeks of age. No difference in heart rate or cardiac output was evident between any of the groups; however stroke volume which was significantly increased in the 16 week ZDF group was no longer different between ZDF and LC at 36 weeks (Table 2). The fact that stroke volume was increased at the earlier, but not the later time point, is significant as this could indicate that the intrinsic stretch response of the heart (Frank-Starling) was an adaptational response while the ventricle continued to remodel. Ejection fraction which was $43 \%$ at 16 weeks decreased to $24 \%$ in the 36 week ZDF group. Overall, these results indicate that there was progressive dilatation of the LV chamber.

Neither maximum nor minimum first derivative of LV pressure $(\mathrm{dP} / \mathrm{dt}$; an indicator of myocardial contractility) was different between groups at either time point. The maximum and minimum first derivative of $\mathrm{LV}$ volume $\left(\mathrm{dV} / \mathrm{dt}_{\max }=\right.$ left ventricular ejection rate during systole, and $\mathrm{dV} / \mathrm{dt}_{\min }=$ peak rate of passive diastolic filling of the left ventricle, respectively) were higher in the 16-week-old ZDF versus LC. There was a significant increase in maximal and minimal $\mathrm{dV} / \mathrm{dt}$ between 36-week-old $\mathrm{ZDF}$ and age-matched LC hearts (Table 2). Additionally, there was a trend $(\mathrm{p}=0.09)$ toward an increase in optimal volume for maximum $\mathrm{dP} / \mathrm{dt}(\mathrm{Vol} @ \mathrm{dP} / \mathrm{dt} \max )$ in the ZDF group at 16 weeks; this increase became statistically significant at 36 weeks compared to LC $(\mathrm{p} \leq 0.05)$. These changes in volume @ dP/dt suggest that in order to maintain contractility the heart has adapted to optimize actin and myosin filament overlap enabling more cross bridge 
formation during contraction. Lastly, we analyzed the time constant of LV pressure decay, Tau, as a measurement of LV relaxation according to Weisfeldt et al. ${ }^{19,20}$ Tau was increased in the ZDF group at both 16 and 36 weeks, compared to age-matched LC groups ( $22 \pm 1$ vs. $13 \pm 0.4 \mathrm{msec}, \mathrm{p} \leq 0.01$, at 16 weeks; and $16 \pm 0.5$ vs. $13 \pm 0.5 \mathrm{msec}, \mathrm{p} \leq 0.05$, at 36 weeks). Collectively, these overall changes in LV chamber morphology and function are characteristic of diastolic cardiomyopathy in diabetic patients, and also of diastolic heart failure which is an emerging clinical manifestation in heart failure patients.

Renal structural and functional assessment. As shown in Table 1, both left and right kidney weights were appreciably increased in the ZDF group, compared to LC, as early as 16 weeks of age. At 36 weeks kidney weights were still significantly increased above age-matched LC but not different from values seen at 16 weeks. Water intake was increased by six-fold at 16 weeks and remained elevated at 36 weeks of age in ZDF rats relative to LC. Urine output in the ZDF group was increased eightfold as early as 10 weeks of age (Fig. 1). By 16 weeks urine output was elevated 20-fold above LC and remained at this level at 36 weeks of age. Figure 2 illustrates the morphological changes in the kidneys from ZDF animals. Of these animals, 14\% showed signs of moderate levels of hydronephrosis at 16 weeks of age (Table 3). At 36 weeks of age, evidence of a shift to mostly mild to moderate hydronephrosis was also apparent in the lean control group. However, the 36-week-old ZDF group exhibited predominately moderate to severe signs of hydronephrosis (Table 3, Fig. 2). Hyperfiltration caused by diabetes induced vasodilatation may significantly contribute to the progression of this form of obstructive uropathy in the ZDF rat. $^{21}$

Excretion of urinary albumin was unchanged at 16 weeks, rela-

tive to controls, but was markedly increased at 24 weeks and progressed further at 36 weeks (Fig. 3). Urinary creatinine levels were also significantly decreased at all time points relative to LC purportedly because of urine dilution. The ratio of urinary albumin to creatinine, an indicator of microalbuminuria, remained constant in the lean control animals, but increased significantly in ZDF rats as early as 10 weeks of age, and significantly increased further between 10 and 36 weeks in ZDF rats (Table 4). Lastly, we performed correlation analysis by linear regression between cardiac parameters (e.g., volume and function) and renal function parameters. Significant correlation was found in the 36 week old ZDF group between urinary albumin and stroke work $\left(\mathrm{r}^{2}\right.$ value $\left.=0.94, \mathrm{p}=0.02\right)$. Moreover, urinary creatinine was positively correlated with cardiac output in the 36 weeks old ZDF group $\left(r^{2}\right.$ value $=0.67$, $\mathrm{p}=0.04)$.

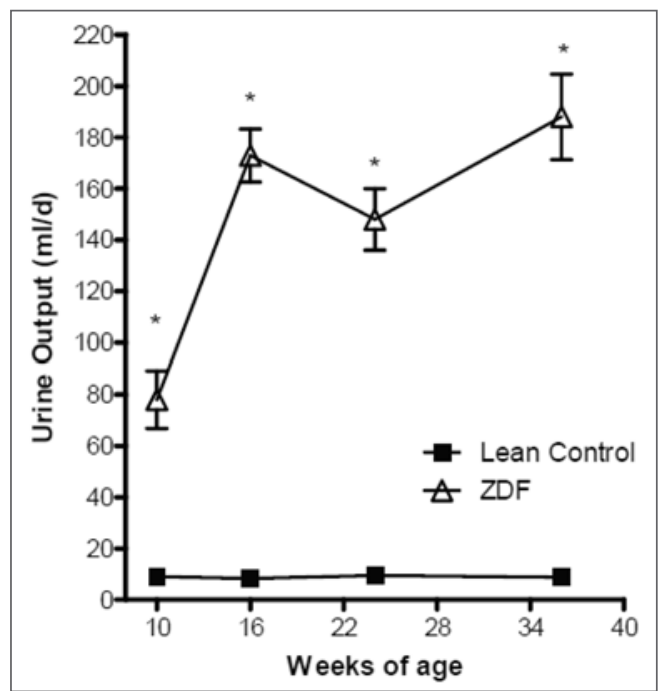

Figure I. Comparison of 24 hour urine output in Lean Control and Zucker diabetic fatty (ZDF) rat kidneys at 10, 16,24 and 36 weeks of age. Urine output is significantly increased in ZDF animals as early as 10 weeks of age and remains markedly increased at all time points relative to lean controls. Values are mean $\pm S D$. *denotes $p \leq 0.0$ I versus age matched lean control.

Figure 2. Representative images of hydronephrosis in Lean Control (LC) and Zucker diabetic fatty (ZDF) rats at 16 and 36 weeks of age. Kidneys were cut across the cross-sectional axis of the hillar region. Eviage with hydronephrosis being more severe in the diabetic animals.

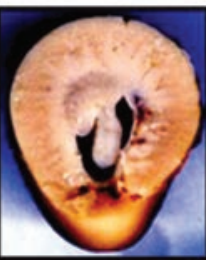

Mild

LC 36 Weeks

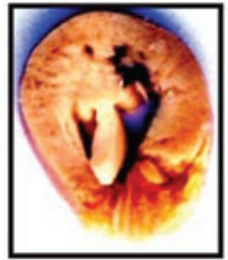

Moderate ZDF 16 Weeks

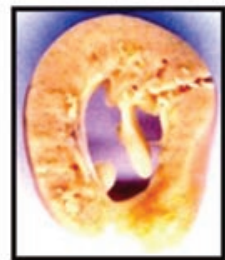

Severe ZDF 36 Weeks

Table 3. Scoring and distribution of hydronephrosis in lean control (LC) and zucker diabetic fatty (ZDF) rat kidneys at 16 and 36 weeks of age

\begin{tabular}{|c|c|c|c|c|}
\hline & $\begin{array}{l}\text { Lean } \\
\text { control }\end{array}$ & ZDF & $\begin{array}{l}\text { Lean } \\
\text { control }\end{array}$ & ZDF \\
\hline & $\begin{array}{l}16 \text { weeks } \\
\text { of age }\end{array}$ & $\begin{array}{l}\text { I6 weeks } \\
\text { of age }\end{array}$ & $\begin{array}{l}36 \text { weeks } \\
\text { of age }\end{array}$ & $\begin{array}{c}36 \text { weeks } \\
\text { of age }\end{array}$ \\
\hline Normal & $5(7 I)$ & I (I4) & $0(0)$ & $0(0)$ \\
\hline Mild & 2 (29) & 5 (7I) & $2(28)$ & I (I0) \\
\hline Moderate & 0 & I (14) & $5(77)$ & $6(60)$ \\
\hline Severe & 0 & 0 & $0(0)$ & $3(30)$ \\
\hline
\end{tabular}

Briefly, kidney sections were assigned a value of either; (0) minimal or no spacing between the papilla and calyx, (I) definitive but mild calyceal spacing with normal papillary shape, (2) calyceal dilatation and compression of the papilla, and (3) extreme distension of the calyx, compaction of the lateral cortex and severe papillary dilatation. Values are presented as frequency with percent of total animals in parentheses. 


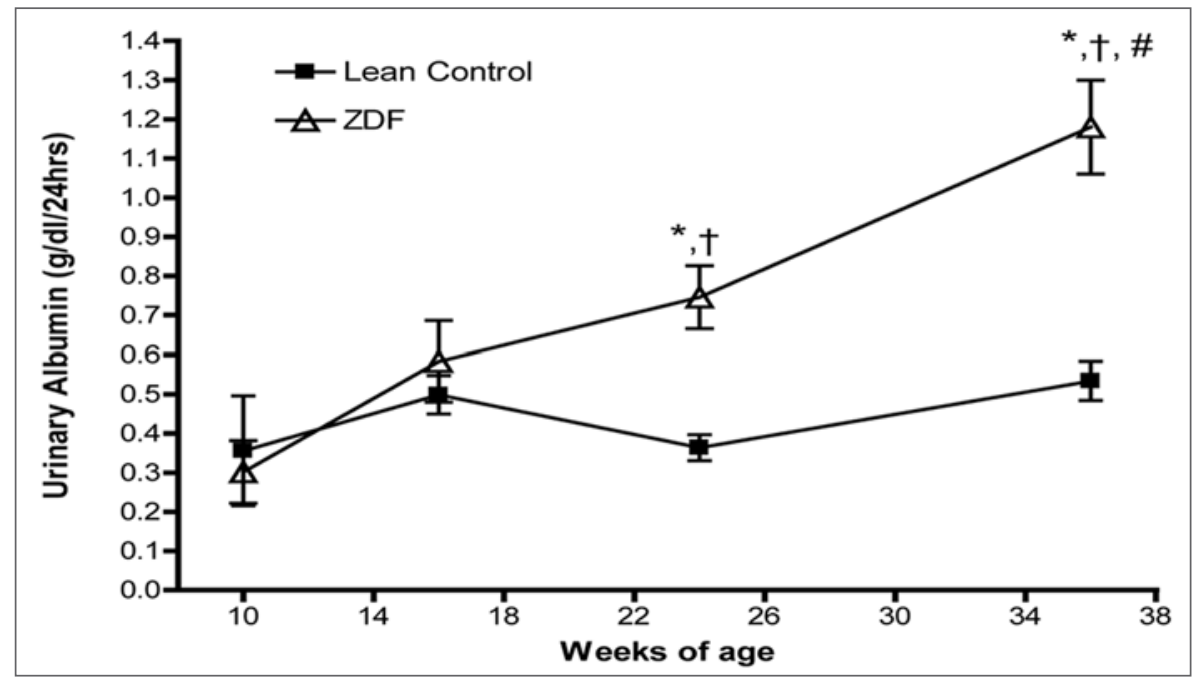

Figure 3. Temporal course of 24 hour urinary excretion of albumin from Lean Control (LC) \& Zucker diabetic fatty (ZDF) rat kidneys at 10, 16, 24 and 36 weeks of age. Excretion of urinary albumin was unchanged at 10 or 16 weeks of age, relative to LC, but was markedly increased at 24 weeks and progressed further at 36 weeks relative to LC as well as the 10 and 16 weeks of age values in the same animals. Values are mean \pm SD. *denotes $p \leq 0.0$ I versus age matched lean control. ${ }^{\dagger} P \leq 0.01$ versus 10 weeks of age ZDF. ${ }^{\#}<0.05$ vs. 24 weeks of age ZDF.

Table 4. Urinary excretion of creatinine and albumin by LC \& ZDF rats at 10, 16, 24 and 36 weeks of age

\begin{tabular}{|c|c|c|c|c|c|}
\hline & & $\begin{array}{c}10 \\
\text { weeks }\end{array}$ & $\begin{array}{c}\text { I6 } \\
\text { weeks }\end{array}$ & $\begin{array}{c}24 \\
\text { weeks }\end{array}$ & 36 weeks \\
\hline \multirow[t]{2}{*}{$\begin{array}{c}\text { Lean } \\
\text { Control }\end{array}$} & & $8.3 \pm 0.5$ & $\begin{array}{c}10.5 \pm \\
0.5\end{array}$ & $11.7 \pm 0.6$ & $12.8 \pm 1.4$ \\
\hline & $\begin{array}{c}\text { Albumin/ } \\
\text { Creatinine } \\
\text { Ratio }\end{array}$ & $42 \pm 16$ & $47 \pm 3$ & $31 \pm 1$ & $4 I \pm 7$ \\
\hline ZDF & & $2.1 \pm 0.3^{*}$ & $1.7 \pm 0.3^{*}$ & $1.6 \pm 0 . I^{*}$ & $1.3 \pm 0.1^{*}$ \\
\hline & $\begin{array}{l}\text { Albumin/ } \\
\text { Creatinine } \\
\text { Ratio }\end{array}$ & $|43 \pm 3|^{*}$ & $\begin{array}{c}350 \pm \\
39 *\end{array}$ & $\begin{array}{c}620 \pm \\
74 * \dagger\end{array}$ & $\begin{array}{l}865 \pm \\
245^{* \dagger}\end{array}$ \\
\hline
\end{tabular}

Values are mean \pm SEM. *denotes $\mathrm{p} \leq 0.0$ I versus age matched lean control. ${ }^{\dagger} \mathrm{P}<0.05$ versus 10 weeks of age.

\section{Discussion}

Guyton's model of cardiorenal syndrome illustrates the pathophysiologic interconnection between the heart and kidney organ systems. $^{22}$ Due to the interrelated nature of their function, changes in one system (cardiovascular) can catalyze changes in the other (renal) which lead to an adverse feedback cycle involving neurohormonal, systemic and local inflammatory mechanisms. However, the point at which the collective effects of ventricular and renal dysfunction becomes greater than their individual pathologies remains to be elucidated. Clinical studies demonstrate a strong link between symptomatic heart failure and renal dysfunction, but raise questions as to which is the true secondary illness. ${ }^{11}$ A recent study by Marsh et al. ${ }^{12}$ reported altered diastolic relaxation as well as the presence of hydronephrosis in the ZDF rat at 14 weeks of age. On the other hand, work by Fredersdorf et al. ${ }^{23}$ investigating insulin's affect on myocardial morphology and function in non insulin dependent diabetes concluded that at 19 weeks of age the ZDF rat exhibited LV hypertrophy and enhanced contractility as assessed by echocardiography. Schafer et al. ${ }^{13}$ also showed that at 37 weeks of age both glomerulosclerosis and proteinuria were present in the ZDF rat. However, in that study, only heart rate and minimum first derivative of LV pressure (minimum and maximum $\mathrm{dP} / \mathrm{dt}$ ) were decreased in ZDF animals compared to LC, whereas multiple indices of LV systolic function and compliance were not significantly different. Because of the limited amount of simultaneous/parallel information on the development of diabetic cardiomyopathy and renal pathology, we sought to investigate the kinetics of development of changes in left ventricular and renal morphology and function in an animal model of type II diabetes.

Left ventricular morphology and functional assessment. We observed that significant changes in LV chamber morphology occurred in the untreated ZDF animals as a diabetes-induced adaptation to maintain overall function. Specifically, type II diabetic rats had significantly increased left ventricular end systolic and end diastolic volume(s) compared to LC animals as early as 16 weeks of age. Stroke volume was also significantly increased at the same time. Additionally, the rate of volume change in the $\mathrm{LV}$ as indicated by minimum and maximum first derivative of $\mathrm{LV}$ volume $(\mathrm{dV} / \mathrm{dt})$ was also elevated in the 16 -week-old ZDF versus age-matched LC. These findings are consistent with the previous findings by Fredersdorf et al. ${ }^{23}$ which demonstrated that at 19 weeks of age the ZDF rat exhibited enhanced contractility. Ultimately, the response of the heart is to maintain cardiac output and thus preserve mean arterial pressure. Initially in other forms of heart failure, the stretch of the myocytes due to end diastolic volume (also known as preload) seeks to maximize overlap potential for actin and myosin filaments within the existing sarcomeres a phenomenon known as the Frank-Starling mechanism. By this means, renal blood flow and glomerular filtration rate would supposedly be able to maintain normal physiologic function at the 16 weeks of age endpoint as increased systolic blood pressure in this model is associated with renal injury. ${ }^{24,25}$ Chronically, dilatation of the LV chamber allows the heart to maintain cardiac output by adding sarcomeres (contractile units) in a parallel or in series fashion to the preexisting sarcomeres. Eventually, a point is reached where the ability of the heart to further compensate is exhausted and the contractile force of the muscle becomes ineffective and heart begins to fail. ${ }^{26,27}$ At this stage, ventricular mass is no longer increased relative to the enlargement of the chamber volume which is what we observed at the 36 weeks of age 
time point. However, in this model of type II diabetes it remains uncertain as to whether this is an adaptational response to worsening cardiac function or expansion of blood volume due to renal impairment as suggested by others. ${ }^{28,29}$

The difference in LV mass in ZDF rats, compared to LC, is an interesting observation. Indeed, changes in LV mass and or geometry greatly affect the overall function of the heart, and are typically a progressive response to chronic physiologic stress such as alterations in cardiac output due to altered hemodynamic load on the heart. ${ }^{30}$ Although overt hypertension was not evident in these animals (Table 2), wall stiffening (as indicated by increased Tau), which commonly occurs in diabetic cardiomyopathy, would necessitate chamber dilation. Regardless of etiology (i.e., volume overload, pressure overload or myocardial injury) persistent elevation in ventricular wall stress initiates cardiac remodeling that results in; (1) initial ventricular dilatation to maintain stroke volume and thus cardiac output, (2) subsequent cardiac dysfunction due to excessive remodeling, and (3) ultimately decompensated heart failure. ${ }^{31}$ Recent clinical studies on left ventricular hypertrophy (LVH) in type II diabetes, based on echocardiography, indicate that there are also a significant number of normotensive individuals which do not present with indication(s) of LVH. ${ }^{32-34}$ The untreated ZDF animals appear to be similar to this clinical phenotype in which there is limited (or inadequate) hypertrophy.

Renal morphology and function. The progression of proteinuria in the Zucker diabetic fatty rat has been documented before, ${ }^{17,35-37}$ but without parallel studies on cardiac function. Recent studies by Bickel et al. ${ }^{38,39}$ as well as Maddox and cowork$\mathrm{ers}^{40}$ found that, even with the presence of mild changes in glomerular morphology in 24-week-old ZDF animals, there was no difference in creatinine clearance, compared to age-matched lean controls. The albumin to creatinine ratio, an indicator of microalbuminuria, was significantly different after 24 weeks of age. The association between microalbuminuria and cardiovascular risk is well established, however only recently has it been recognized as having predictive value of heart failure. ${ }^{11}$ Although we did not measure glomerular filtration, we did observe moderate to severe hydronephrosis at 36 weeks in ZDF animals. Previous studies have detailed similar findings of hydronephrosis in the ZDF rat, ${ }^{12,41}$ however, the underlying etiology remains uncertain. Since both the LC and ZDF animals presented with this pathology, the leptin receptor deficiency is probably not the cause. However, Marsh et al. ${ }^{12}$ postulated an epigenetic cause as a potential underlying heritable mechanism behind hydronephrosis in these animals. Recent work by El Osta et al. ${ }^{42}$ demonstrated that temporary hyperglycemia induced persistent epigenetic changes in the promoter of the nuclear factor kappaB (subunit p65 NFKB) which lasted for at least 6 days under subsequent normoglycemic conditions. While the ZDF rat is only one of many models of diabetes, this same phenomenon of hydronephrosis also occurs in the KKay transgenic mouse model of type II diabetes. ${ }^{43}$

Renal and cardiovascular function in diabetes. While our findings indicate that EDV for the 16 week old ZDF animals was markedly increased, similar to the findings of Marsh et al. ${ }^{12}$ this occurred prior to significant changes in proteinuria or the presence of significant hydronephrosis. However, the albumin/ creatinine ratio was increased at both 10 and 16 weeks in the ZDF animal (Table 4). The changes in LV chamber morphology and altered myocardial relaxation (Tau) as early as 16 weeks in association with evidence of renal impairment suggest that diabetes induced cardiac and renal pathophysiology may develop in parallel with one another in the ZDF animal.

Nevertheless, only $20 \%$ of diabetics with microalbuminuria progress to nephropathy and only $20 \%$ of those individuals will progress to end stage renal disease 20 years after onset of nephropathy. ${ }^{7}$ In contrast to renal complications, diabetics have a 1.4 -fold higher chance of developing congestive heart failure. ${ }^{44}$ It should be recognized that renal pathology may not be apparent until it is fairly severe, e.g., only after loss of $80-90 \%$ of functional nephrons. Measurement of urinary glucose is not a good diagnostic indicator of diabetes because glucose does not appear in urine until the renal threshold is exceeded. Similarly changes in albuminuria and creatininemia probably become apparent only after significant loss of renal function. Renal disease may be silent, but just as harsh as cardiovascular pathology; the latter may just be more easily detected. However, it is clinically evident that once the "functional reserve" of the kidney has been exhausted there is a compounding affect that severely impacts survival. ${ }^{45}$

\section{Materials and Methods}

Experimental design. All Animal Use Protocols were approved by the Institutional Animal Care and Use Committee (IACUC) and conform with the Guide for the Care and Use of Laboratory Animals, published by the US National Institutes of Health (NIH Publication no. 85-23, revised 1996). The Zucker Diabetic Fatty rats $(\mathrm{ZDF})$ rat is an inbred leptin receptor-deficient model of adult onset type II diabetes displaying insulin resistance, hyperinsulinemia and hyperglycemia. Male ZDF $(f a / f a)$ and lean control heterozygous litter mates (LC; fa/?) were obtained at 6 weeks of age $(-200 \mathrm{~g})$ from Charles River Laboratories (Wilmington, MA). All animals were maintained on Purina 5008 rat chow with water ad libitum. Animals were housed two to a cage in a $12: 12-\mathrm{h}$ dark/light cycle controlled room. At the age of 10 weeks, after confirming hyperglycemia via tail vein blood samples, the animals were divided into two experimental groups: (1) lean control rats (LC; $n=7)$ and untreated ZDF rats $(n=7)$ sacrificed at 16 weeks of age, and (2) lean control rats (LC; $n=7)$ and untreated ZDF rats $(n=9)$ sacrificed at 36 weeks of age. These time points were chosen as they best correspond to the early (14-17 weeks of age) and later stage (24-37 weeks of age) ranges of animal ages used in previous studies, focused on either cardiac ${ }^{14-16,23,46}$ or renal pathophysiology. ${ }^{13,17,18,36,41,47}$ Prior to sacrifice, left ventricular systolic and diastolic structural and functional parameters were assessed; plasma samples were collected, the heart and kidneys were removed, rinsed in ice cold PBS and weighed, and then portions were either snap frozen in liquid nitrogen for biochemical analysis or placed in Telley's fixative for histological analysis.

Left ventricular functional assessment. As previously described, LV systolic and diastolic pressure and volume functional analysis was performed in anesthetized rats using a high- 
fidelity Millar pressure/volume (SPR-838; Millar Instruments, Houston, TX) conductance catheter inserted into the LV via the right carotid artery. ${ }^{48-50}$ For calibration, this measurement technique requires that a small amount $(0.1 \mathrm{ml})$ of $15 \%$ saline be introduced into the blood volume of the anesthetized animal at the end of the experimental protocol as a correction factor for the blood-LV tissue interface. Data were analyzed using PVAN 3.5 software from Millar Instruments.

Assessment of renal structural and functional changes. The right kidney was cut along a sagital plane in the hilar region and fixed by immersion in Telley's fixative. Following staining with hematoxylin and eosin, hydronephrosis was calculated by criteria previously described. ${ }^{12,41}$ Briefly, kidney sections were assigned a value of either; (0) minimal or no spacing between the papilla and calyx, (1) definitive but mild calyceal spacing with normal papillary shape, (2) calyceal dilatation and compression of the papilla, and (3) extreme distension of the calyx, compaction of the lateral cortex and severe papillary dilatation.

Urinary measurements. Animals were individually housed in metabolic cages for measurement of twenty-four hour water intake and urine production. Urine samples were stored at $-80^{\circ} \mathrm{C}$ until assayed for urinary albumin using an ELISA assay (Cayman Chemicals, Ann Arbor, MI) and urinary creatinine by a colorimetric kit assay based on the Jaffe reaction (Bio-Rad, Hercules, CA). From these measurements, the albumin to creatinine ratio was determined.

Statistics. Statistical analyses were performed with Graphpad 5.0 software (Prism Inc., San Diego, CA). All grouped data are expressed as means \pm SEM unless otherwise noted. Data comparisons for pressure/volume parameters between agematched LC and ZDF were made by student's t-test. Renal functional measurements were analyzed by repeated measures one way analysis of variance. A p-value of $\leq 0.05$ was judged significant.

\section{Conclusion}

The findings herein indicate that changes in LV chamber morphology occurred in the untreated ZDF animals as early as 16 weeks of age as a diabetes-induced adaptation to maintain overall function. Compared to lean controls, excretion of urinary albumin, albumin-creatinine ratio and hydronephrosis also progressively worsened with age. In summary it appears that both cardiac and renal complications are developing in parallel, as there is evidence of progressive structural and functional changes in both the heart and kidney, starting as early as 16 weeks, without evidence that one precedes or causes the other in the ZDF model of type II diabetes.

\section{Acknowledgements}

We would like to thank Lindsey Gainey, and Jenifer McClarty for their technical assistance. This work was funded in part by Juvenile Diabetes Research Foundation Innovative Award (D.B.M.), South Carolina Centers of Biomedical Research Excellence (COBRE) for cardiovascular disease (D.B.M.) and NIH Research Grant, DK-19971 (J.W.B.).

\section{References}

1. Dagenais GR, Gerstein HC, Holman R, et al. Effects of ramipril and rosiglitazone on cardiovascular and renal outcomes in people with impaired glucose tolerance or impaired fasting glucose: results of the Diabetes REduction Assessment with ramipril and rosiglitazone Medication (DREAM) trial. Diabetes Care 2008; 31:1007-14.

2. Maione A, Nicolucci A, Craig JC, et al. Protocol of the Long-term Impact of RAS Inhibition on Cardiorenal Outcomes (LIRICO) randomized trial. J Nephrol 2007; 20:646-55.

3. McQueen MJ, Lonn E, Gerstein HC, Bosch J, Yusuf S. The HOPE (Heart Outcomes Prevention Evaluation) Study and its consequences. Scand J Clin Lab Invest Suppl 2005; 240:143-56

4. Kannel WB, Hjortland M, Castelli WP. Role of diabetes in congestive heart failure: the Framingham study. Am J Cardiol 1974; 34:29-34.

5. Mainous AG, III, Baker R, Koopman RJ, et al. Impact of the population at risk of diabetes on projections of diabetes burden in the United States: an epidemic on the way. Diabetologia 2007; 50:934-40.

6. Department of Health and Human Services CfDCaP. National Diabetes Fact Sheet 2007, www.cdc.gov. Diabetes Data and Trends 2009.

7. American Diabetes Association. National Diabetes Fact Sheet, 2002. Accessed online at http://www.diabetes. org/diabetesstatistics/national-diabetic-fact-sheet.jsp. 2006.

8. Boudina S, Abel ED. Diabetic cardiomyopathy revisited. Circulation 2007; 115:3213-23.

9. El-Atat FA, Stas SN, McFarlane SI, Sowers JR. The relationship between hyperinsulinemia, hypertension and progressive renal disease. J Am Soc Nephrol 2004; 15:2816-27.
10. Schiffrin EL, Lipman ML, Mann JF. Chronic kidney disease: effects on the cardiovascular system. Circulation 2007; 116:85-97.

11. Gilbert RE, Connelly K, Kelly DJ, Pollock CA, Krum $\mathrm{H}$. Heart failure and nephropathy: catastrophic and interrelated complications of diabetes. Clin J Am Soc Nephrol 2006; 1:193-208.

12. Marsh SA, Powell PC, Agarwal A, Dell'Italia LJ, Chatham JC. Cardiovascular dysfunction in Zucker obese and Zucker diabetic fatty rats: role of hydronephrosis. Am J Physiol Heart Circ Physiol 2007; 293:2928 .

13. Schafer S, Linz W, Bube A, et al. Vasopeptidase inhibition prevents nephropathy in Zucker diabetic fatty rats. Cardiovasc Res 2003; 60:447-54.

14. Wang P, Lloyd SG, Zeng H, Bonen A, Chatham JC. Impact of altered substrate utilization on cardiac function in isolated hearts from Zucker diabetic fatty rats. Am J Physiol Heart Circ Physiol 2005; 288:2102-10.

15. Yue TL, Bao W, Gu JL, et al. Rosiglitazone treatment in Zucker diabetic Fatty rats is associated with ameliorated cardiac insulin resistance and protection from ischemia/ reperfusion-induced myocardial injury. Diabetes 2005; 54:554-62.

16. Schafer S, Huber J, Wihler C, Rutten H, Busch AE, Linz W. Impaired left ventricular relaxation in type 2 diabetic rats is related to myocardial accumulation of $\mathrm{N}$ (epsilon)-(carboxymethyl) lysine. Eur J Heart Fail 2006; 8:2-6.

17. Janiak P, Bidouard JP, Cadrouvele C, et al. Longterm blockade of angiotensin AT1 receptors increases survival of obese Zucker rats. Eur J Pharmacol 2006; 534:271-9.

18. Chander PN, Gealekman O, Brodsky SV, et al. Nephropathy in Zucker diabetic fat rat is associated with oxidative and nitrosative stress: prevention by chronic therapy with a peroxynitrite scavenger ebselen. J Am Soc Nephrol 2004; 15:2391-403.
19. Weisfeldt ML, Scully HE, Frederiksen J, Rubenstein JJ, Pohost GM, Beirholm E, et al. Hemodynamic determinants of maximum negative $\mathrm{dP} / \mathrm{dt}$ and periods of diastole. Am J Physiol 1974; 227:613-21.

20. Weiss JL, Frederiksen JW, Weisfeldt ML. Hemodynamic determinants of the time-course of fall in canine left ventricular pressure. J Clin Invest 1976; 58:751-60.

21. De Vriese AS, Stoenoiu MS, Elger M, et al. Diabetesinduced microvascular dysfunction in the hydronephrotic kidney: role of nitric oxide. Kidney Int 2001; 60:202-10

22. Bongartz LG, Cramer MJ, Doevendans PA, Joles JA Braam B. The severe cardiorenal syndrome: 'Guyton revisited'. Eur Heart J 2005; 26:11-7.

23. Fredersdorf S, Thumann C, Ulucan C, et al. Myocardia hypertrophy and enhanced left ventricular contractility in Zucker diabetic fatty rats. Cardiovasc Pathol 2004; 13:11-9.

24. Suzaki Y, Ozawa Y, Kobori H. Intrarenal oxidative stress and augmented angiotensinogen are precedent to renal injury in Zucker diabetic fatty rats. Int J Biol Sci 2007; 3:40-6.

25. Siddiqui AH, Ali Q, Hussain T. Protective role of angiotensin II subtype 2 receptor in blood pressure increase in obese Zucker rats. Hypertension 2009; 53:256-61

26. Janicki JS, Brower GL, Gardner JD, et al. Cardiac mast cell regulation of matrix metalloproteinase-related ventricular remodeling in chronic pressure or volume overload. Cardiovasc Res 2006; 69:657-65.

27. Damman K, Navis G, Smilde TD, et al. Decreased cardiac output, venous congestion and the association with renal impairment in patients with cardiac dysfunction. Eur J Heart Fail 2007; 9:872-8.

28. Ritz E. Left ventricular hypertrophy in renal disease: beyond preload and afterload. Kidney Int 2009; 75:771-3. 
29. Ramchandra R, Hood SG, Frithiof R, May CN. Discharge properties of cardiac and renal sympathetic nerves and the impaired control of blood volume in heart failure. Am J Physiol Regul Integr Comp Physiol 2009.

30. Carabello BA. Concentric versus eccentric remodeling. J Card Fail 2002; 8:258-63.

31. Janicki JS, Brower GL, Gardner JD, Chancey AL, Stewart JA Jr. The dynamic interaction between matrix metalloproteinase activity and adverse myocardial remodeling. Heart Fail Rev 2004; 9:33-42.

32. Dawson A, Morris AD, Struthers AD. The epidemiology of left ventricular hypertrophy in type 2 diabetes mellitus. Diabetologia 2005; 48:1971-9.

33. Salmasi AM, Rawlins S, Dancy M. Left ventricular hypertrophy and preclinical impaired glucose tolerance and diabetes mellitus contribute to abnormal left ventricular diastolic function in hypertensive patients. Blood Press Monit 2005; 10:231-8.

34. Sato A, Tarnow L, Nielsen FS, Knudsen E, Parving $\mathrm{HH}$. Left ventricular hypertrophy in normoalbuminuric type 2 diabetic patients not taking antihypertensive treatment. QJM 2005; 98:879-84.
35. Dominguez JH, Wu P, Hawes JW, et al. Renal injury: similarities and differences in male and female rats with the metabolic syndrome. Kidney Int 2006; 69:196976.

36. Coimbra TM, Janssen U, Grone HJ, et al. Early event leading to renal injury in obese Zucker (fatty) rats with type II diabetes. Kidney Int 2000; 57:167-82.

37. Etgen GJ, Oldham BA. Profiling of Zucker diabetic fatty rats in their progression to the overt diabetic state. Metabolism 2000; 49:684-8.

38. Bickel CA, Verbalis JG, Knepper MA, Ecelbarger CA Increased renal $\mathrm{Na}-\mathrm{K}-\mathrm{ATPase} \mathrm{NCC}$, and beta-ENaC abundance in obese Zucker rats. Am J Physiol Renal Physiol 2001; 281:639-48.

39. Bickel CA, Knepper MA, Verbalis JG, Ecelbarger CA Dysregulation of renal salt and water transport proteins in diabetic Zucker rats. Kidney Int 2002; 61:2099110

40. Maddox DA, Alavi FK, Silbernick EM, Zawada ET Protective effects of a soy diet in preventing obesitylinked renal disease. Kidney Int 2002; 61:96-104.

41. Vora JP, Zimsen SM, Houghton DC, Anderson S Evolution of metabolic and renal changes in the ZDF/ Drt-fa rat model of type II diabetes. J Am Soc Nephro 1996; 7:113-7.
42. El-Osta A, Brasacchio D, Yao D, Pocai A, Jones PL, Roeder RG, et al. Transient high glucose causes persistent epigenetic changes and altered gene expression during subsequent normoglycemia. J Exp Med 2008; 205:2409-17.

43. Ninomiya $H$, Inomata $T$, Ogihara K. Microvasculature of hydronephrotic kidneys in KK-A(Y) mice. J Vet Med Sci 2000; 62:1093-8.

44. Mundet X, Pou A, Piquer N, et al. Prevalence and incidence of chronic complications and mortality in a cohort of type 2 diabetic patients in Spain. Prim Care Diabetes 2008; 2:135-40.

45. Joseph J, Koka M, Aronow WS. Prevalence of moderate and severe renal insufficiency in older persons with hypertension, diabetes mellitus, coronary artery disease, peripheral arterial disease, ischemic stroke or congestive heart failure in an academic nursing home. J Am Med Dir Assoc 2008; 9:257-9.

46. Wang P, Chatham JC. Onset of diabetes in Zucker diabetic fatty (ZDF) rats leads to improved recovery of function after ischemia in the isolated perfused heart. Am J Physiol Endocrinol Metab 2004; 286:725-36.

47. Leehey DJ, Singh AK, Alavi N, Singh R. Role of angiotensin II in diabetic nephropathy. Kidney Int Suppl 2000; 77:93-8.

48. Murray DB, Gardner JD, Brower GL, Janicki JS. Effects of Non-Selective Endothelin-1 Receptor Antagonism on Cardiac Mast Cell-Mediated Ventricular Remodeling in Rats. Am J Physiol Heart Circ Physiol 2008.

49. Wei CL, Valvano JW, Feldman MD, Nahrendorf M, Peshock R, Pearce JA. Volume catheter parallel conductance varies between end-systole and end-diastole. IEEE Trans Biomed Eng 2007; 54:1480-9.

50. Pacher P, Nagayama T, Mukhopadhyay P, Batkai S, Kass DA. Measurement of cardiac function using pressure-volume conductance catheter technique in mice and rats. Nat Protoc 2008; 3:1422-34. 


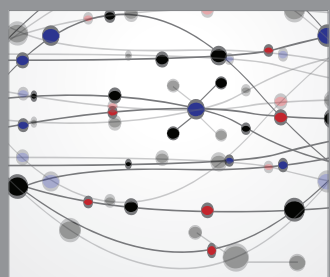

The Scientific World Journal
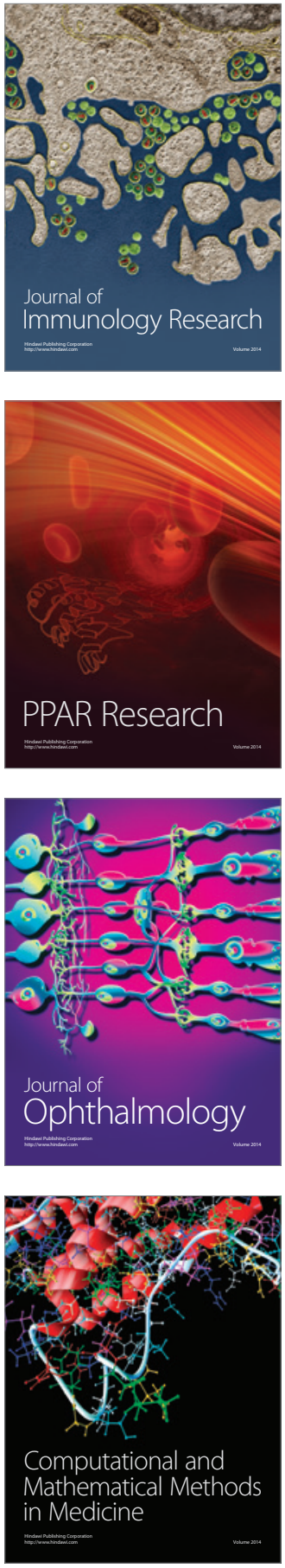

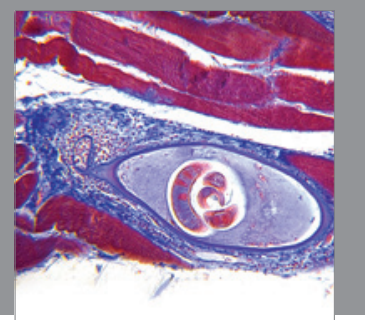

Gastroenterology

Research and Practice
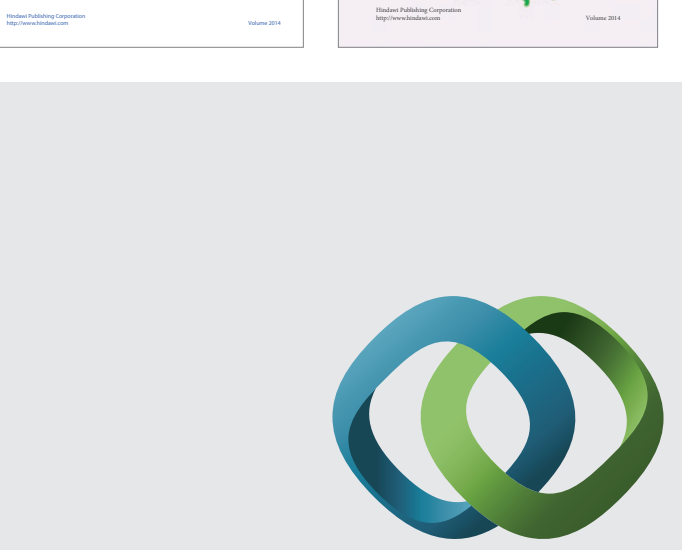

\section{Hindawi}

Submit your manuscripts at

http://www.hindawi.com
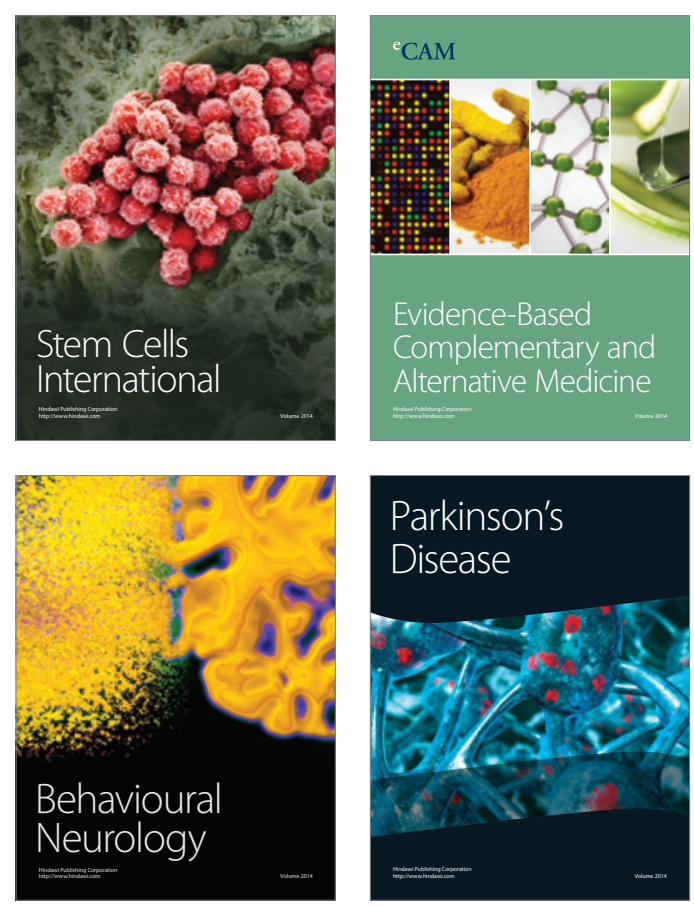

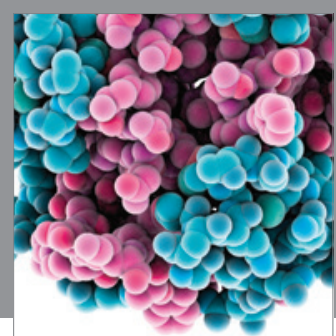

Journal of
Diabetes Research

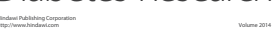

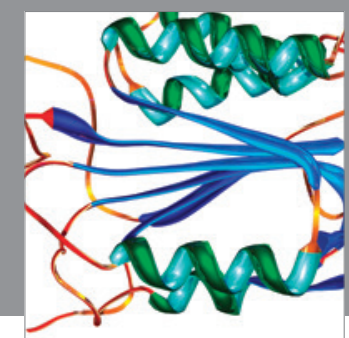

Disease Markers
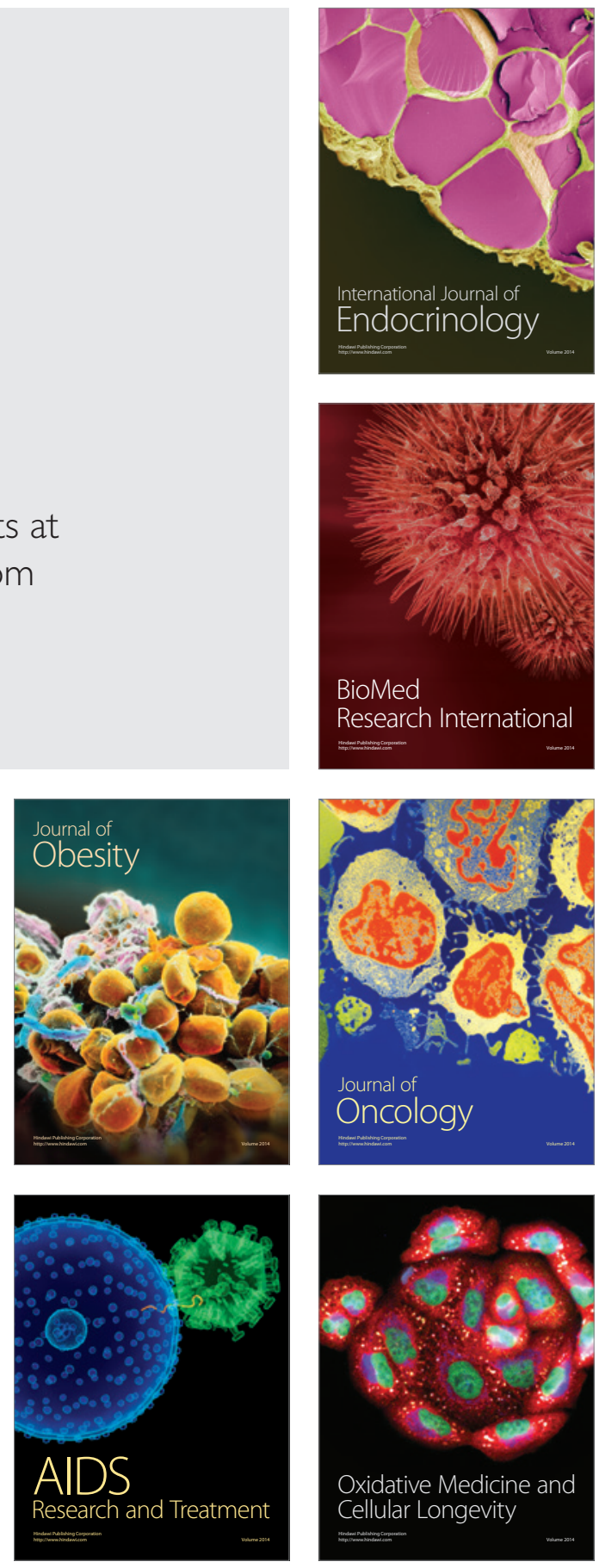